\title{
CORTICOSTEROIDS USE: A SURVEY ON THE LEVEL OF KNOWLEDGE AND PRESCRIPTION PATTERN OF DOCTORS IN MAIDUGURI, NORTH-EASTERN NIGERIA
}

${ }^{1}$ Yerima A, ${ }^{1}$ Adamu AA, ${ }^{2}$ Bakki B, ${ }^{1}$ Muhammad M, ${ }^{2}$ Amali AO, ${ }^{1}$ Hassan AA.
PMB 1414, Maiduguri, Borno state, Nigeria
Department of Medicine, University of Maiduguri Teaching Hospital,
Maiduguri, Borno State, Nigeria
Correspondence and reprint request to: Dr Abubakar Yerima; Department of Medicine,
University of Maiduguri Teaching Hospital, PMB 1414, Maiduguri, Borno state, Nigeria
Email: abybuni@yahoo.com Phone: +2348126696544, +2340838789601

\begin{abstract}
Background: Despite the high prescription rates of Corticosteroids (CS), physicians have poor knowledge of the long-term effects and monitoring of CS. Objectives: To evaluate the knowledge of doctors in Maiduguri, Nigeria, on the use, adverse effects, and monitoring of corticosteroids. Methodology: A cross sectional survey involving 248 consenting doctors practicing in Maiduguri between $1^{\text {st }}$ of January and $30^{\text {th }}$ of March, 2020. Results: Of the 248 doctors surveyed, 161 completed the survey (response rate of $64.9 \%$ ). Mean age was $34 \pm 5.6$ years with $95(59 \%)$ males. Majority $(74.5 \%)$ had only MBBS and 125 (77.6\%) were practicing in a tertiary setting, $43(26.7 \%)$ and $38(23.6 \%)$ were from Medicine and General Outpatient Department respectively. Seventyfour $(50.7 \%)$ had been practicing for one to five years. All had prescribed CS before. Duration of practice was not associated with frequency of CS prescription $\left(\chi^{2}=24.08, p=0.091\right)$. Prednisolone was the most commonly prescribed CS (48.4\%) while, the oral route was the preferred mode of prescription by $80(49.7 \%)$ respondents. Seventy-three $(45.3 \%)$ prescribed CS for allergy, respiratory diseases, and dermatological complaints. Most $(67.7 \%)$ were not aware of the dosage classification of CS but 99 (61.5\%) were aware of guidelines for stopping CS during treatment. Majority (92.5\%) were aware of multiple adverse effects of CS with $24.2 \%$ reporting Cushingoid changes. Seventy-eight (48.4\%) routinely assess patients for adverse effects. Only, $4(2.5 \%)$ and 6 $(3.7 \%)$ of respondents routinely screen for osteoporosis and tuberculosis respectively. Less than $44 \%$ and $22 \%$ routinely screen for drug-drug interaction and CS complications respectively. Conclusion: There is low level of knowledge regarding the use and monitoring of CS in Maiduguri.
\end{abstract}

Key words: Adverse effect, Corticosteroids, Doctors in Maiduguri, Knowledge, Prescription pattern

\section{INTRODUCTION}

Corticosteroids (CS) are potent anti-inflammatory drugs commonly prescribed in medical practice. The mechanisms of action of CS are not fully understood and the drugs have a wide range of uses in treating allergic, inflammatory, respiratory, musculoskeletal, dermatologic and endocrine disorders. They can be prescribed in oral,

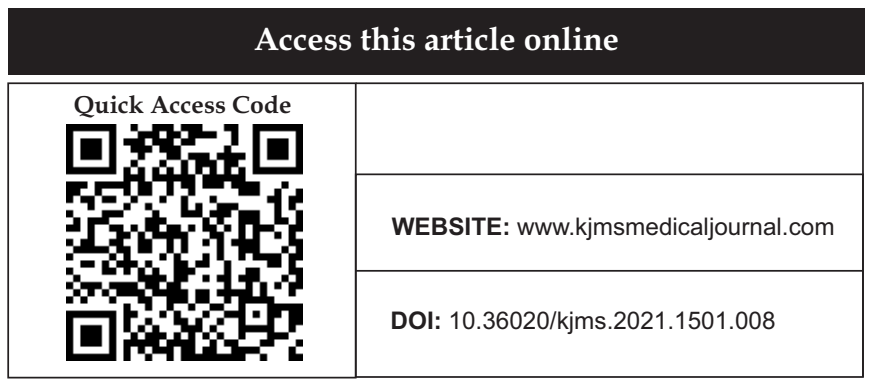

intravenous, inhaled or topical forms, at low or high doses and for replacement or treatment purposes. ${ }^{1,2}$ These potent medications have a lot of adverse effects too. Adverse effects of medical importance include weight gain, fluid retention, hyperglycemia, hypertension and immunosuppression, cataracts, peptic ulcer disease, hypothalamo-pituitary axis (HPA) suppression and osteoporosis.

About $1.2 \%$ of adults in the United States received oral CS at any point in time from 1999 to 2008 , out of which $28.8 \%$ of them received oral CS for greater than or equal to 5 years. 4 In France, the prevalence of CS use was $14.7 \%$ in 2007 , which rose to $17.1 \%$ in 
2014 (a corresponding rise of $14.1 \%$ when compared with 2007). The rise was more pronounced in individuals aged 50-69 years, and prednisolone was the commonly prescribed CS. ${ }^{5}$ The economic burden in terms of frequent prescriptions and side effects of CS is also high. This high burden is attributed to the additional cost of treating fractures, diabetes mellitus, peptic ulcer diseases, myocardial infarction, stroke and malignancies such as lymphoma. ${ }^{6}$

This high prescription rate of CS is not without reasons. Yousefi $e t \mathrm{al}^{7}$ highlighted that the reasons for irrational prescription of CS can fall under four categories: physicians' lack of knowledge, patientphysician relationship in terms of monetary cost, poor availability of proper alternative medicines and weak supervision of regulatory bodies. Rational prescription of drugs requires that the physician first identify the patient's problem (the diagnosis), specify the therapeutic objective, choose a treatment of proven efficacy and safety, writes an accurate prescription and provide the patient with clear information and instructions. After some time, the physician monitors the results of the treatment and stops the treatment if the problem is solved. ${ }^{8}$

Despite the ubiquitous prescription of CS by doctors, there exist no clear-cut general guidelines for the prescription and monitoring of CS; however, some scientific organizations have developed recommendations for dosing and treatment regimens as well as monitoring the adverse effects of CS in patients on long-term treatment. ${ }^{9,10}$

In addition, studies have shown that physicians and patients alike have poor knowledge of the longterm effects of CS, especially its effect on the Hypothalamo-Pituitary Axis (HPA), bone metabolism, use of steroid cards, dose adjustment during stress and monitoring of CS therapy. ${ }^{11,12}$ Of the more than 1.6 million prescriptions of CS to over 240,000 patients in the United Kingdom (UK), only $4.0 \%$ to $5.5 \%$ were concomitantly prescribed with anti-bone resorption medications. [12] However, in the France cohort, $27.4 \%$ were placed on bisphosphonate, $55 \%$ on vitamin $\mathrm{D}$ and calcium, and $10.8 \%$ were on proton pump inhibitors (in the absence of non-steroidal anti-inflammatory drugs or aspirin). ${ }^{5}$
To the best of our knowledge and literature search, we found no data on the survey of knowledge and prescription pattern of CS in Nigeria. Additionally, the duo of lack of clear guidelines for CS usage and the 'irrational' prescription of CS by physicians will no doubt increase the burden of the adverse effect and economic cost of using CS. Conducting such a survey will highlight some of the unmet issues concerning CS use.

The objective of the survey is to evaluate the knowledge of doctors in Maiduguri, northeastern Nigeria, on the use, adverse effects, and monitoring of corticosteroids and possibly make recommendations on the need to educate doctors on the use of CS.

\section{MATERIALS AND METHOD}

Study area: The study was conducted in Maiduguri (latitude 11.50N, longitude 13.09E), the capital city of Borno state, North Eastern Nigeria. It has a University Teaching hospital, two state specialist hospitals, a Neuropsychiatric Hospital, a nursing home, a chest clinic, a skin clinic and few private hospitals with about 300 doctors, practicing predominantly in the Teaching hospital, State specialist hospital and the Neuropsychiatric hospital. ${ }^{13}$

Study design: A cross sectional survey involving 248 doctors practicing in Maiduguri.

Study population: All consenting medical doctors practicing in the major hospitals in Maiduguri between January and March 2020.

Study protocol: A self-administered questionnaire was pretested by 15 doctors to assess the feasibility of using the questionnaire and areas of improvement were modified. The questionnaires were distributed to 248 consenting doctors in all the major government hospitals in Maiduguri by three research assistants. Personal identities of the responding doctors were not obtained and completion of the survey was completely voluntary. The forms were serially numbered and each questionnaire was given a unique identification number to avoid duplication. The questionnaire had four sections comprising (1) Demographic profile and practice setting of the doctors; (2) The prescription pattern which includes the frequency of prescription, commonly prescribed steroids, route of administration, 
indications for prescription, the highest and lowest dose ever prescribed in prednisolone equivalents, the shortest and longest duration ever prescribed, classification of CS dosages, how to stop long and short term CS and if the doctor is aware of any guidelines for CS use; (3) Aspect on knowledge of the adverse effect of CS used and if doctors routinely screen at baseline for risk factors predisposing to CS toxicity and drug-drug interactions; (4) In the last section, participants were asked if they routinely monitor patients on CS to assess their blood glucose, blood pressure, lipid profile, Bone Mineral Density (BMD), annual height, ophthalmologic exams, and adrenal function and perform lateral spine radiograph. The questionnaires were retrieved after one week of distribution by the research assistants.

Ethical approval was not required for this study.

Data collection and analysis: Collected data were entered into an Excel sheet and coded before transfer to SPSS version 21. Only completed questionnaires were analyzed and data were not collected from non-responders. Unanswered questions were tagged as no response. Descriptive statistics were used. Continuous variables were subjected to a test of normality and presented as mean \pm SD or median [IQR] where appropriate. Answers were categorized into Yes, No and No response and presented as proportions and percentages. The relationship between categorical variables was determined by the Chi-square test. A p-value of $<0.05$ was considered statistically significant.

\section{RESULTS}

\section{Demographics}

One hundred and sixty-one doctors out of 248 completed the survey giving a response rate of $64.9 \%$. Their mean age was $34 \pm 5.6$ years and comprised of 95 (59\%) males. The majority $(74.5 \%)$ had MBBS as their highest qualification with 9 $(5.6 \%)$ specialists. Forty-three $(26.7 \%)$ were from the Medicine department, while 38 (23.6\%) were from the general outpatient department. Seventy-four $(50.7 \%)$ had been practising for one to five years with $125(77.6 \%)$ practising in a tertiary setting. Table 1 shows the demographic pattern of the respondents.
Table 1: Demographic profile of the respondents

\begin{tabular}{|c|c|c|}
\hline Variable & Categories & Number (\%) \\
\hline Age & Mean age & $34 \pm 5.6$ \\
\hline \multirow[t]{2}{*}{ Gender } & Male & $95(59)$ \\
\hline & Female & $66(41)$ \\
\hline \multirow[t]{5}{*}{ Qualification } & MBBS & $120(74.5)$ \\
\hline & BDS & $6(3.7)$ \\
\hline & MSc & $10(6.2)$ \\
\hline & Fellows & $9(5.6)$ \\
\hline & Others & $14(8.7)$ \\
\hline \multirow[t]{11}{*}{ Departments } & Medicine & $43(26.7)$ \\
\hline & Surgery & $13(8.1)$ \\
\hline & Paediatrics & $13(8.1)$ \\
\hline & Gynaecology & $12(7.5)$ \\
\hline & Lab. & $16(9.9)$ \\
\hline & Medicine & \\
\hline & Maxillofacial & $19(11.8)$ \\
\hline & ENT & $1(0.6)$ \\
\hline & Psychiatry & $4(2.5)$ \\
\hline & Anaesthesia & $2(1.2)$ \\
\hline & Others & $38(23.6)$ \\
\hline \multirow{5}{*}{$\begin{array}{l}\text { Duration of } \\
\text { practice (years) }\end{array}$} & $1-5$ & $74(50.7)$ \\
\hline & $6-10$ & $41(28.1)$ \\
\hline & $11-15$ & $27(18.5)$ \\
\hline & $16-20$ & $3(2.1)$ \\
\hline & $>20$ & $1(0.7)$ \\
\hline \multirow[t]{4}{*}{ Practice settings } & Primary & $3(1.9)$ \\
\hline & Secondary & $31(19.3)$ \\
\hline & Tertiary & $125(77.6)$ \\
\hline & Quaternary & $2(1.2)$ \\
\hline
\end{tabular}

$\%$-percentage, MBBS-bachelor of medicine, bachelor of surgery, BDS- bachelor of dental surgery, MSc- Masters in science, lab - Laboratory, ENT- Ear Nose and Throat

\section{Corticosteroids prescription pattern (Table 2)}

All respondents had during their practice prescribed CS at one point or the other. More than half $(59 \%)$, prescribed CS sometimes in their practice, with only one $(0.6 \%)$ prescribing CS always. There was no association between duration of practice and frequency of CS prescription $\left(\chi^{2}=\right.$ 24.08, $\mathrm{p}=0.091)$. The commonest CS prescribed by the respondents was prednisolone (78 [48.4\%]), and the least prescribed was Methylprednisolone (1, $[0.6 \%])$. None of the respondents ever prescribed Fludrocortisone. The oral route was the preferred mode of prescription by $80(49.7 \%)$ respondents.

Seventy-three $(45.3 \%)$ prescribed CS for a combination of various ailments such as allergy, respiratory diseases, and dermatological complaints while $8(5.0 \%)$ prescribed it solely due to some haematological disorders. The shortest and 
longest duration of CS prescription by the respondents was a median of 5 [IQR 2-7] days and 1 [IQR 0.5 -3] month, respectively. Most (67.7\%) respondents were not aware of the dosage classification of CS into low, medium, high, very high and pulse therapy. Of the 21 (13\%) respondents that attempted to classify the dosages, $18(11.1 \%)$ considered low dose as 2.5 to $5 \mathrm{mg}$ of prednisolone equivalent per day, while $2(1.2 \%)$ and one $(0.6 \%)$ respondents considered $50 \mathrm{mg}$ and 7.5 $\mathrm{mg}$ respectively, as low dose CS. The highest dose of prednisolone equivalent ever prescribed by the respondents was $1250 \mathrm{mg}$ and the lowest dose was $5 \mathrm{mg}$.

Short-course and long-term CS therapy were tapered gradually by $79(49.1 \%)$ and $127(78.9 \%)$ respondents, respectively with 99 (61.5\%) respondents aware of guidelines for stopping CS during treatment. Eighty-nine (55.3\%) respondents recommended the use of steroid cards for those on long term treatment. There was no association between awareness of guidelines for stopping CS and the level of qualifications of the respondents $\left(X^{2}\right.$ $=12.91, \mathrm{p}=0.141$ ).

Table 2: Prescription pattern of corticosteroids by Doctors in Maiduguri

\begin{tabular}{|c|c|c|}
\hline Variable & Category & Number (\%) \\
\hline \multirow[t]{4}{*}{ Frequency of CS prescription } & Rarely & $34(21.1)$ \\
\hline & Sometimes & $95(59.0)$ \\
\hline & Frequently & $31(19.3)$ \\
\hline & Always & $1(0.6)$ \\
\hline \multirow[t]{5}{*}{ Commonest CS prescribed } & Prednisolone & $78(48.4)$ \\
\hline & Hydrocortisone & $42(26.1)$ \\
\hline & Dexamethasone & $22(13.7)$ \\
\hline & Methylprednisolone & $1(0.6)$ \\
\hline & Fludrocortisone & $0(0)$ \\
\hline \multirow[t]{5}{*}{ Commonest form prescribed } & Oral preparation & $80(49.7)$ \\
\hline & Intravenous & $50(31.1)$ \\
\hline & Intramuscular & $9(5.6)$ \\
\hline & Topical & $5(3.1)$ \\
\hline & Combination & $17(10.5)$ \\
\hline \multirow[t]{5}{*}{ Diseases treated } & Allergies & $44(27.3)$ \\
\hline & Respiratory illness & $29(18.1)$ \\
\hline & Dermatology & $7(4.3)$ \\
\hline & Haematological & $8(5.0)$ \\
\hline & Combination & $73(45.3)$ \\
\hline \multirow[t]{2}{*}{ Duration of prescription } & Short duration (days) & Median 5[IQR2-7] \\
\hline & Long duration (months) & Median 1[IQR 0.5-3] \\
\hline \multirow[t]{2}{*}{ Awareness of dose classification } & Yes & $43(26.7)$ \\
\hline & No & $109(67.7)$ \\
\hline Highest dose prescribed & $1250 \mathrm{mg}$ & Median 34 [IQR 20-42] \\
\hline Lowest dose prescribed & $5 \mathrm{mg}$ & Median 5[IQR 5-20] \\
\hline \multirow[t]{2}{*}{ Awareness of guidelines for stopping CS } & Yes & $99(61.5)$ \\
\hline & No & $44(27.3)$ \\
\hline \multicolumn{3}{|l|}{ Tapering CS } \\
\hline \multirow[t]{3}{*}{ Short term } & Abruptly & $57(35.4)$ \\
\hline & Gradually & $79(49.1)$ \\
\hline & According to guidelines & $18(11.2)$ \\
\hline \multirow[t]{3}{*}{ Long term } & Abruptly & $4(2.5)$ \\
\hline & Gradually & $127(78.9)$ \\
\hline & According to guidelines & $17(10.6)$ \\
\hline \multirow[t]{3}{*}{ Recommend steroid card } & Yes & $89(55.3)$ \\
\hline & No & $52(32.3)$ \\
\hline & No response & $20(12.4)$ \\
\hline
\end{tabular}

\%- percent, CS- Corticosteroids, IQR- Interquartile range 


\section{Adverse effects of corticosteroids (Table 3 )}

Regarding adverse effects of CS, 149 (92.5\%) respondents were aware of the multiple (more than 6) adverse effects of CS. The single most common adverse effect reported during the practice of respondents was Cushingoid changes (39 [24.2\%]) and the least observed was HPA suppression (2 [1.2\%]), while 90 (55.9\%) reported a combination of side effects. Other side effects reported were immunosuppression (12 [7.5\%]), diabetes (8 [5.0\%]), osteonecrosis (7 [4.3\%]) and dermatologic $(3[1.9 \%])$.
Less than half $(48.4 \%)$ of respondents routinely assess patients for the risk factors of developing CS adverse effects. The two most common screening done by respondents were blood pressure (117 [72.7\%]) and weight (82 [50.9\%]) measurements. Only $4(2.5 \%)$ and $6(3.7 \%)$ respondents routinely screen patients for osteoporosis and tuberculosis, respectively. Routine screening for drug-drug interaction with CS was poor $(<44 \%)$ with most $(60.2 \%)$ respondents only screening for antidiabetic medications.

Table 3: Respondent's awareness of adverse effects, and routine screening for risk factors of corticosteroids toxicity and drug-drug interactions

\begin{tabular}{|c|c|c|c|}
\hline \multirow[t]{2}{*}{ Variable } & \multicolumn{3}{|c|}{ Category N (\%) } \\
\hline & Yes & No & No response \\
\hline Aware of $=6$ side effect of CS & $149(92.5)$ & $12(7.5)$ & - \\
\hline Routinely assess for risk factor & $78(48.4)$ & $74(46.0)$ & $9(5.6)$ \\
\hline \multicolumn{4}{|l|}{ Variables routinely screened } \\
\hline Height & $54(33.5)$ & $95(59.0)$ & $12(7.5)$ \\
\hline Weight & $82(50.9)$ & $70(43.5)$ & $9(5.6)$ \\
\hline BMI & $62(38.5)$ & $89(55.3)$ & $10(6.2)$ \\
\hline Blood pressure & $117(72.7)$ & $36(22.4)$ & $8(5.0)$ \\
\hline CBC & $40(24.8)$ & $109(67.7)$ & $12(7.5)$ \\
\hline FBG & $70(43.5)$ & $80(49.9)$ & $11(6.5)$ \\
\hline Lipid profile & $34(21.1)$ & $113(70.2)$ & $14(8.7)$ \\
\hline BMD & $4(2.5)$ & $140(87.0)$ & $17(13.0)$ \\
\hline Tuberculosis & $6(3.7)$ & $142(88.2)$ & $13(8.1)$ \\
\hline Pregnancy & $65(40.4)$ & $80(49.7)$ & $16(9.9)$ \\
\hline \multicolumn{4}{|l|}{ Ask for drug-drug interaction } \\
\hline Anticonvulsant & $40(24.8)$ & $106(65.8)$ & $15(9.3)$ \\
\hline Anticoagulant & $46(28.6)$ & $99(61.5)$ & $16(9.9)$ \\
\hline Antifungal & $28(17.4)$ & $119(73.9)$ & $14(8.7)$ \\
\hline Anti-diabetics & $97(60.2)$ & $56(33.4)$ & $8(5.0)$ \\
\hline Antiviral & $38(23.6)$ & $107(66.5)$ & $16(9.90$ \\
\hline Antibiotics & $46(28.6)$ & $100(62.1)$ & $15(9.3)$ \\
\hline Diuretics & $19(11.8)$ & $123(76.4)$ & $19(11.8)$ \\
\hline NSAIDs & $61(37.9)$ & $87(54.0)$ & $13(8.1)$ \\
\hline Live Vaccine & $22(13.7)$ & $124(77.0)$ & $15(9.3)$ \\
\hline
\end{tabular}

$\mathrm{N}=$ number, \%-percent, BMI-Body mass Index, CBC-Complete Blood Count, FBG- Fasting Blood Glucose, BMD-Bone Mineral Density, NSAIDs-Non-Steroidal Anti-Inflammatory Drugs

\section{Monitoring of corticosteroids therapy}

Eighty-two (50.9\%) respondents were aware that they should monitor patients on steroids therapy. Very few $(<22 \%)$ respondents routinely measure the height, BMD, perform lateral spine X-rays, monitor rate of growth, measure lipid levels, fasting blood glucose, assesses cardiovascular risk, perform yearly ophthalmologic exams or assess adrenal insufficiency annually (table 4). When asked if there are absolute contraindications to the use of steroids, 94 (58.4\%) affirmed so, 24 (14.9\%) were not sure, while $43(26.7 \%)$ indicate that, no absolute contraindication exists. 
Table 4: Participant response regarding routing monitoring of corticosteroids therapy

\begin{tabular}{llll}
\hline Variable & \multicolumn{2}{l}{ Response N (\%) } & \\
& Yes & No & No response \\
Routinely monitor & $82(50.9)$ & $67(41.6)$ & $12(7.5)$ \\
Annually assess for & & & \\
Height & $26(16.1)$ & $111(68.9)$ & $24(14.9)$ \\
BMD & $12(7.5)$ & $121(75.2)$ & $28(17.4)$ \\
Lateral spineX-Ray & $14(8.7)$ & $120(74.5)$ & $27(16.8)$ \\
Rate of growth & $34(21.1)$ & $101(62.7)$ & $26(16.1)$ \\
Lipid level & $25(15.5)$ & $108(67.1)$ & $27(16.8)$ \\
CVDx risk & $15(9.3)$ & $115(71.4)$ & $31(19.3)$ \\
FBGafter 48 hours & $29(18.0)$ & $105(65.2)$ & $27(16.8)$ \\
Eye examination & $17(10.6)$ & $114(70.8)$ & $29(18.6)$ \\
Adrenal insufficiency & $23(14.3)$ & $109(67.7)$ & $29(18)$ \\
\hline
\end{tabular}

N - Number, \%-per cent, BMD -Bone Mineral Density, CVDx- Cardiovascular Disease, FBG- Fasting Blood Glucose.

\section{DISCUSSION}

Corticosteroids (CS) are potent anti-inflammatory agents widely used to treat various ailments. Despite their potency, they are not without untoward side effects. Common side effects such as obesity and infections are easily recognized by health workers when patients are placed on longterm CS. However, subtle but heinous adverse effects such as adrenal dysfunction, osteoporosis, cataracts and metabolic complications (dyslipidaemia and hyperglycaemia) are often missed by health care providers. The aforementioned adverse effects are influenced by the CS dosage and duration of use, route of administration, mode of tapering the dose, and improper monitoring of the drugs. Hence, proper prescription and monitoring of patients on such medication is imperative in terms of mitigating the side effects of these drugs.

The survey has highlighted that CS are frequently prescribed by young doctors, mostly in tertiary hospital settings. Prescriptions are mostly done to treat allergic and dermatologic conditions. Prednisolone was the most commonly prescribed CS in its oral form, and the side effect frequently observed was weight gain (Cushingoid appearance). Most physicians were not aware of the dosage classification of CS. In addition, physicians had a paucity of knowledge in terms of screening for risk factors for CS toxicity, osteoporosis, tuberculosis and drug-drug interactions. They also have poor knowledge regarding monitoring of patients on CS to prevent the development of osteoporosis and fractures, diabetes, dyslipidaemia, cataract and adrenal insufficiency.
Most of the hospitals in the province were manned by young doctors and a few specialists reflecting the dominance of that age group in the survey. Oral prednisolone is the most widely prescribed CS in the world. ${ }^{14}$ It is highly potent, cheap and readily available in most places, as such, a lot of doctors find it easier to prescribe. The low prescription of fludrocortisone by the doctors may not be unconnected with the fact that it is mostly used by a specialist in some rare circumstances. Physicians were able to recognize patients with weight gain easily because, even without weighing the patients, the physical changes associated with CS use is often unique. In a population-based study on the assessment of the adverse effect of prednisolone, $90 \%$ of the patient-reported at least one side effect with $70 \%$ reporting weight gain as their main adverse effect. ${ }^{15}$ Poor knowledge regarding dosage classification into low, medium, high, very high or pulse therapy among the doctors may be due to the lack of a standard classification of CS dosage. Most recommendations of CS used were made by professional bodies which are not commonly utilized by general practitioners. ${ }^{9,10,16}$ Practical recommendations ${ }^{14,17}$ require physicians to screen for patients' bone health, gastrointestinal diseases, endocrine disorders, ocular problems, cardiovascular health, vaccinations, infections and mood and cognitive behaviours. The majority of our respondents do not screen for these risk factors aside from hypertension and diabetes mellitus. In addition, despite the common drug-drug interaction that alters the pharmacokinetics of $\mathrm{CS}^{18}$ most physicians do not ask their patients about the 
use of other medications, this may lead to increase the toxicity of CS.

CS therapy is a common iatrogenic cause of osteoporosis termed Glucocorticoid-Induced Osteoporosis (GIOP). About $30 \%$ to $50 \%$ of patients on CS greater than or equal to 3 months develop GIOP. ${ }^{17}$ Patients on CS also have an increased risk of fracture of the spine and hip when compared to patients not taking steroids. ${ }^{19}$ It is recommended that clinicians prescribing CS should counsel their patients about osteoporosis and screen for the GIOP risk factors at the outset of therapy. A Dual-energy x-ray absorptiometry (DEXA) scan should be done at baseline to estimate Bone Mineral Density (BMD) and screen for osteoporosis and osteopenia. ${ }^{14,17}$ Only $2.5 \%$ of our respondents routinely screen for BMD at baseline. This low level of screening for osteoporosis among our respondent is not surprising because of the absence of DEXA scan in most centres in Africa and the absence of clear cut guidelines for monitoring and screening. A similar study from the UK has shown only $4.0 \%$ to $5.5 \%$ of patients on long term steroids were receiving antiosteoporotic drugs concomitantly. ${ }^{12}$ In France, only $12.9 \%$ of patients on CS had DEXA done; however, about $60.6 \%$ of patients at risk of osteoporosis were placed on at least one drug for osteoporosis management. Another intriguing finding in this survey is the low level of awareness of the respondents to screen for tuberculosis (TB), with only $3.7 \%$ of them aware that $\mathrm{TB}$ screening is recommended. The WHO has recommended Systematic testing and treatment for latent $\mathrm{TB}$ infection depending on the countries' TB burden and resources. ${ }^{20}$ Screening for latent tuberculosis is strongly recommended for certain risk groups: adult household contacts of pulmonary tuberculosis cases; patients with silicosis; patients initiating anti-tumour necrosis factor treatment; patients on dialysis; and organ transplant recipients (on immunosuppressive medications) in uppermiddle or high-income countries. ${ }^{21}$ Nigeria is considered a high TB burden country with an estimated TB incidence of 429 (280-609) thousand in 2018 and ranked the highest TB burden country in Africa. ${ }^{22}$ With the high prescription rate of CS in Nigeria, ${ }^{23}$ screening for latent TB is imperative if patients will be on long-term CS. Despite the moderate number of respondents that said they routinely monitor patients on long-term CS, less than $20 \%$ annually screen for a reduction in height, perform lateral spine X-ray, rate of growth, lipid level cardiovascular disease risk, Fasting Blood
Glucose (FBG) after 48 hours, eye examination and adrenal insufficiency. Although there are no clear cut guidelines for these routine assessments ${ }^{17}$ some authorities have recommended screening for these conditions in patients on long-term $\mathrm{CS}^{14}$

We were not able to quantify the knowledge base of the respondents by using cutoff marks. This is because, most of the questions have no clear cut, right or wrong answers. However, this survey has brought to the limelight the low level of knowledge regarding the use and monitoring of CS in our region and the need to improve the capacity of prescribers of CS to monitor the safety of its long term use in their patients.

We recommend that, doctors should have formal training on the prescription and monitoring of CS. In the undergraduate curriculum, there is a need to emphasize on the monitoring and prevention of the adverse effects of CS.

\section{Disclosure}

All authors declare no conflict of interest

\section{Acknowledgement}

We acknowledge the valuable contribution of Prof AM Talle during the development of the questionnaire.

\section{REFERENCE}

1. Timmermans S, Souffriau J and Libert C. A General Introduction to Glucocorticoid Biology. Front. Immunol. 2019; 10:1545. doi: 10.3389/fimmu.2019.01545

2. Ramamoorthy S, Cidlowski JA. Corticosteroids. Rheumatic Disease Clinics of North America. 2016 Feb;42(1):15-31.

3. Rice JB, White AG, Scarpati LM, Wan G, Nelson WW. Long-term Systemic

Corticosteroid Exposure: A Systematic Literature Review. Clinical Therapeutics. 2017 Nov;39(11):2216-29.

4. Overman RA, Yeh J-Y, Deal CL. Prevalence of oral glucocorticoid usage in the United States: a general population perspective. Arthritis Care Res (Hoboken). 2013 Feb;65(2):294-8.

5. Bénard-Laribière $\mathrm{A}$, Pariente $\mathrm{A}$, Pambrun E, Bégaud B, Fardet L, Noize P. Prevalence and prescription patterns of oral glucocorticoids in adults: a retrospective cross-sectional and cohort analysis in France. BMJ Open. 2017 Jul1;7(7):e015905.

6. Manson SC, Brown RE, Cerulli A, Vidaurre 
CF. The cumulative burden of oral corticosteroid side effects and the economic implications of steroid use. Respiratory Medicine. 2009 Jul;103(7):975-94.

7. Yousefi N, Majdzadeh R, Valadkhani M, Nedjat S, Mohammadi H. Reasons for physicians' tendency to an irrational prescription of corticosteroids. Iran Red Crescent Med J. 2012 Nov 10;14(11):724-9.

8. De Vries TPGM, Henning RH, Hogerzeil HV, Fresle DA, Drugs WAP on E, Policy WHOED and M. Guide to good prescribing: a practical manual. 1994 [cited 2020 Dec 21]; Available from:

9. Buttgereit F. SP0160 2018 eular recommendations for the use of glucocorticoid therapy. Ann Rheum Dis. 2018 Jun 1;77(Suppl 2):42.

10. Lamontagne F, Rochwerg B, Lytvyn L, Guyatt GH, Møller MH, Annane D, et al. Corticosteroid therapy for sepsis: a clinical practice guideline. BMJ. 2018 Aug 10;k3284.

11. Grounds K, Khan I, Adlan M, Premawardhana L. Poor knowledge of safety aspects of long-term steroid use among patients and healthcare professionals. Clin Med (Lond). 2017 Aug;17(4):378-80.

12. van Staa TP. Use of oral corticosteroids in the United Kingdom. QJM. 2000 Feb 1;93(2):105-11.

13. Location of Maiduguri - Google Search [Internet]. [cited 2021 Jan 13]. Available https://www.google.com/search?client=fi refox-b-d\&q=location + of + maiduguri

14. Liu D, Ahmet A, Ward L, Krishnamoorthy $\mathrm{P}$, Mandelcorn ED, Leigh R, et al. A practical guide to the monitoring and management of the complications of systemic corticosteroid therapy. Allergy, Asthma \& Clinical Immunology. 2013 Aug 15;9(1):30.

15. Curtis JR, Westfall AO, Allison J, Bijlsma JW, Freeman A, George V, et al. Populationbased assessment of adverse events associated with long-term glucocorticoid use. Arthritis Care \& Research. 2006;55(3):420-6.

16. Miracle X, Di Renzo GC, Stark A,
Fanaroff A, Carbonell-Estrany X, Saling (Coordinators of WAPM Premat E. Guideline for the use of antenatal corticosteroids for fetal maturation. Journal of Perinatal Medicine [Internet]. 2008 Jan 1 [cited 2021 Jan 11];36(3). A $\quad \mathrm{v}$ a $\mathrm{i} \quad 1$ a $\quad$ b 1 e from:https://www.degruyter.com/vie $\mathrm{w} / \mathrm{j} / \mathrm{j} \mathrm{p} \mathrm{m} \mathrm{.} 2008.36$. is s u e 3/jpm.2008.032/jpm.2008.032.xml

17. Caplan A, Fett N, Rosenbach M, Werth VP, Micheletti RG. Prevention and management of glucocorticoid-induced side effects: A comprehensive review. Journal of the American Academy of Dermatology. 2017 Jan;76(1):1-9.

18. Czock D, Keller F, Rasche FM, Häussler U. Pharmacokinetics and pharmacodynamics of systemically administered glucocorticoids. Clin Pharmacokinet. 2005;44:61-98

19. Van Staa TP, Leufkens HGM, Abenhaim L, Zhang B, Cooper C. Use of Oral Corticosteroids and Risk of Fractures. J Bone Miner Res. 2000 Jun 1;15(6):993-1000.

20. Guidelines on the management of latent tuberculosis infection. Geneva: World Health Organization; 2018

21. Getahun H, Matteelli A, Abubakar I, Hauer B, Pontali E, Migliori GB. Advancing global programmatic management of latent tuberculosis infection for at risk populations. Eur Respir J. 2016 M a y ; 47 ( 5 ): $1327-30$. d o i : http:/ / dx.doi.org/10.1183/13993003.0044 9-2016 PMID: 27132266

22. Global Tuberculosis Report 2019 [Internet]. [cited 2021 Jan 12]. Available $\begin{array}{llll}\mathrm{f} & \mathrm{r} & \mathrm{O} & \mathrm{m}\end{array}$ https://www.who.int/teams/global$\mathrm{tuberculos}$ is - program m / t breports/global-report-2019

23. Iloh K. K., Ayuk A. C., Obumneme-Anyim I. N., Oguonu T. Corticosteroid use in bronchial asthma: prescription patterns of doctors in Southeast Nigeria. Int. J. Med. Health Dev. 2017; 22 (2):107-112. $10.4314 / /$ jcm.v22i2.8

Cite this article as: Yerima A, Adamu AA, Bakki B, Muhammad M, Amali AO, Hassan AA. Corticosteroids Use: A Survey on the Level of Knowledge and Prescription Pattern of Doctors in Maiduguri, North-Eastern Nigeria. KJMS 2021; 15(1): 65 - 72. 